\title{
Study on the Survival and Reproductive Performance of Sterile Male Glossina pallidipes
}

\author{
Tadese Setegn $^{1, ~ *, ~ T e s f u ~ F e k e n s a ~}{ }^{2}$, Emiru Siyoum $^{3}$, Solomon Mekonnen $^{4}$ \\ ${ }^{1}$ Ethiopian Veterinary Drug and Animal feed Administration and Control Authority, Addis Ababa, Ethiopia \\ ${ }^{2}$ Ethiopian Biodiversity Institute, Addis Ababa, Ethiopia \\ ${ }^{3}$ Addis Ababa University, College of Natural Sciences, Addis Ababa, Ethiopia \\ ${ }^{4}$ Kality Tsetse Fly Rearing and Irradiation Center, Addis Ababa, Ethiopia \\ Email address: \\ tsetsetadese@gmail.com (T. Setegn) \\ ${ }^{*}$ Corresponding author
}

\section{To cite this article:}

Tadese Setegn, Tesfu Fekensa, Emiru Siyoum, Solomon Mekonnen. Study on the Survival and Reproductive Performance of Sterile Male Glossina pallidipes. International Journal of Biomedical Science and Engineering. Vol. 4, No. 3, 2016, pp. 13-21.

doi: $10.11648 /$ j.ijbse.20160403.11

Received: May 6, 2016; Accepted: May 20, 2016; Published: June 30, 2016

\begin{abstract}
Laboratory investigation was conducted to know the effect of irradiation (sterility) on reproductive performance of females G. pallidipes mated with sterile and fertile males under temperature of $23-25^{\circ} \mathrm{C}$ and $75-80 \%$ relative humidity. Completely randomized designs with three replications were followed throughout the experiments. The irradiation effects on male G. pallidipes at different doses of irradiation were checked using, 60Gy, 80Gy, 100Gy and 120Gy. Results showed that at highest doses the sterility effects on male Glossina pallidipes were significantly lower than lowest doses $(\mathrm{P}<0.05)$ on pupae production and emergence of adults. On the other hand, the highest dose (120Gy) caused abortion of egg/larvae significantly higher than the lower dose (60Gy) $(\mathrm{P}<0.05)$. In other investigation which was aimed to assessing the competitiveness of sterile malestofertile males in a cage at ratios of 9 sterile: 1 fertile males, 7 sterile to 3 fertile males, 5 sterile to 5 fertile males and 3 sterile to 7 fertile males, the results showed that the ratio with the highest number of sterile $(9: 1)$ in the cage caused significantly low number of pupae and number of adults emerged from pupae than those with lower number of sterile males (3:7) $(\mathrm{P}<0.05)$. Similarly, the ratio with the highest sterile males $(9: 1)$ resulted in significantly higher number of egg/larvae abortion than those with lower number of sterile males (3:7) ratio $(\mathrm{P}<0.05)$. In the present study, survival of male G. pallidipes irradiated with $120 \mathrm{~Gy}$ three days after emergence from pupae was significantly higher than males irradiatedone and ten days after emergence from pupae $(\mathrm{P}<0.05)$. This may indicate that irradiated males may need to rest up to 7 or 10 days before released to the field. The importance of sterilization using appropriate dose, the appropriate ratio of sterile to fertile males and the time at which sterility was done efficiently all are relevant.
\end{abstract}

Keywords: Tsetse Fly, Trypanosomosis, SIT, Irradiation and Kality

\section{Introduction}

Tsetse flies (Glossina spp) transmit sleeping sickness in humans and nagana in livestock, which attacks the blood and nervous system of its victims. It is caused by the protozoa trypanosomes and the tsetse fly acts as a vector as it feeds on blood of animals and humans. Sleeping sickness is always fatal without the appropriate medical treatment and trypanosomiasis is one of the most widespread and important constraints to agricultural development in Africa and also has a major impact on social welfare [13].

The general distribution of tsetse flies is determined principally by climate and influenced by altitude, vegetation, and presence of suitable host animals [9]. Tsetse flies in Ethiopia are confined to southern and western regions between longitude 330 and 380 East and latitude 50 and 120 North which amounts to about $200,000 \mathrm{Km}^{2}$. Tsetse infested areas lied in the low lands and also in the river valleys of Blue Nile, Baro Akobo, Didessa, Ghibe andOmo. Out of the nine regions of Ethiopia five (Amhara, 
Beninshangul Gumuz, Gambella, Oromia and Southern Nation Nationalities and peoples) are infested with more than one species of tsetse flies [9]. To date five species of Glossina (Glossina morsitans submorsitans, G. Pallidipes, G. tachnoides, G. f. fuscipes and G. longipennis) have been recorded from Ethiopia [1].

The morsitansgroup is of great importance in the transmission of animal trypanosomosis and the palpalis group in the transmission of human sleeping sickness (leak, 1998). Adult Glossina species are dull in appearance, varying in colour from a light yellowish brown to a dark blackish brown. In some species the abdomen may have alternate darker and lighter bands. The smallest species (G. tachinoides) is $6-8 \mathrm{~mm}$ long and the largest (G. pallidipes) 10-14 mm [17].

Tsetse vector control methods relying on large scale bush clearing and aerial spraying methods are no longer used due to environmental concerns. Tsetse control currently relies on two bait systems: insecticide-treated traps and targets and insecticide treated livestock. Sterile Insect Technique (SIT) has also been used in efforts to eradicate tsetse flies in some areas. The SIT relies on the production of large numbers of the target insect in specialized production centers, the sterilization of the males pupae or adult fly (or sometimes both sexes), and the sustained and systematic release of the sterile males over the target area in numbers large enough in relation to the wild male population to out compete them for wild females mating of the sterile insects with virgin, native females will result in no offspring. Therefore, the objectives of the present investigation were to study on the compatibility of sterile male Glossina pallidipes in terms of survival and reproductive performance as a contribution to SIT focused tsetse fly management.

\section{Materials and Methods}

\subsection{Location and Experimental Conditions}

All the investigations in the present studies were carried out at Kality Tsetse fly Rearing and Irradiation Center, Addis Ababa following the Center's standard procedure for irradiation of male flies.

\subsection{Experimental Flies (Glossina Pallidipes)}

All pupae and adult flies used for the experiments were derived from the stock colonies of Glossina pallidipes, which were initially collected from the field in and around Arbamench and are now being reared at Kality Tsetse fly Rearing and Irradiation Center. The pupae were placed and maintained at $75-80 \%$ relative humidity and at $23-25^{\circ} \mathrm{C}$ temperature regime. The pupae were kept for 25 days before being transferred into different cages where they emerged as adult after 25-30 days. The flies after emergence were kept in holding cages (diameter of $20 \mathrm{~cm}$ length and width of $5 \mathrm{~cm}$ ) at a density of 30-40 flies per cage with netting on top and bottom for feeding and collection of the larvae. Similar to the pupae, adult flies were also maintained at a temperature regime of $23-25^{\circ} \mathrm{C}$ and a relative humidity of $75-80 \%$ [5].

\subsection{Sex Separation}

A cage that contains tsetse fly populations (30-40) at first day of emergence from pupae was introduced into a refrigerator of $4^{\circ} \mathrm{C}$ for 5-10 min. to inactivate (chill) the flies. Each fly was taken out of the cage one at a time and observed at the tip of the abdomen under compound microscope to determine their sex. The male has a pointed abdomen and superior claspers or external genital which are heavily pigmented. On the other hand, the female has an abdomen which is truncated and pale in its appearance.

\subsection{Irradiation of Male Glossina}

A total of 60 male tsetse flies (1 day old) were chilled at $4^{\circ} \mathrm{C}$ for 5-10 min. fifteen male flies were placed in a small cage and irradiated in bulk in a pre-chilled vacuum flask with 120Gy in a ${ }^{60} \mathrm{Co}$ Gammacell 200 for 56.4 seconds. Gray (Gy) is the International System (SI) unit of radiation which equals to $100 \mathrm{rad}$ (radiation-absorbed dose). The treated males then allowed to rest for 3 hour before feeding and placed in the rearing room at a temperature of $23-25^{\circ} \mathrm{C}$ and relative humidity of $75-80 \%$ [5]

\subsection{Materials}

The materials used for the experiments in the present work included, holding cages (diameter of $20 \mathrm{~cm}$ and width of $5 \mathrm{~cm}$ ) with netting on top and bottom for feeding and collection of the larvae, feeding tray (anodized aluminum), heated mat (with an adjustable heat source), 96\% irradiated bovine blood and silicon membrane to cover warm blood. All these materials were used following the Center's standard procedure.

\section{Methodology}

Emerged flies were separated into male and female, using a chiller set at $4^{\circ} \mathrm{C}$. The flies were kept in cages (diameter of $20 \mathrm{~cm}$ and width of $5 \mathrm{~cm}$ ) with a density of 30-40 flies per cage with netting on top and bottom for feeding and collection of the larvae. The newly emerged males were given irradiation treatments $(60 \mathrm{~Gy}$ with $28.2 \mathrm{sec}$., $80 \mathrm{~Gy}$ with $37.6 \mathrm{sec}$., and 100Gy with $47 \mathrm{sec}$. and $120 \mathrm{~Gy} 56.4 \mathrm{sec}$.) on day one following emergence and then allowed to mix with the newly emerged 30 female adults in a cage. Sterile males were allowed to mate at a ratio of 10:30 (1:3) male to female per cage. One group of untreated males with females of the same ratio as those treated was kept as control. The experiment was designed in a completely randomized design (CRD) in three replications. All groups of the experiment were kept for up to 30 days at $75-80 \% \mathrm{Rh}$ and $23-25^{\circ} \mathrm{C}$. Abortion of eggs/larvae and production of pupae were recorded from days 20-30 and 18-30 days, respectively at the time of feeding. Feeding was done three times in a week using 96\% irradiated bovine blood [6]. Females were dissected to observe blockages of pupae in the uterus and findings were recorded as number of pupae produced. 
Fecundity was expressed as the number of pupae produced per mature female per day, taking day 18 following emergence as the first larviposition day. The pupae collected from each group were maintained at $75-80 \% \mathrm{Rh}$ and $23-25^{\circ} \mathrm{C}$ for 25-30 days [5]. The number of adult flies emerged from each group were then recorded and analyzed.

As described above (experiment I), emerged flies were separated into male and female using a chiller set at $4{ }^{\circ} \mathrm{C}$. The flies were kept in cages (diameter of $20 \mathrm{~cm}$ and width of $5 \mathrm{~cm}$ ) with a density of 30-40 flies per cage with netting on top and bottom for feeding and collection of the larvae. the experiment was conducted in such a way that newly emerged males were given irradiation with dose of $120 \mathrm{~Gy}$ and same age of newly fertile males were mated sterile to fertile males at different ratios ( 9 sterile to 1 fertile male, 7 sterile to 3 fertile males, 5 sterile to 5 fertile males and 3 sterile to 7 fertile males) were allowed to mate with females in different cages that contain 30 females each. On the other hand, 10 fertile males and 10 sterile males were allowed to mate into 30 females as a control. Mating was hence done at a 1:3 (male: female) ratio. The experiment was designed in a completely randomized design (CRD) in three replications. Insects were kept for 30 days at $75-80 \% \mathrm{Rh}$ and $23-25^{\circ} \mathrm{C}$. Abortion of egg/larvae from days 20- 30 and number of pupae produced which started from day 18-30 day were recorded at time of feeding. Feeding was done three times a week using 96\% irradiated bovine blood [5]. After day 30, female flies were dissected to observe blockages of pupae in the uterus and findings were recorded from each group as number of pupae produced. Similar to experiment I, the pupae collected from each group were maintained at $75-80 \% \mathrm{Rh}$ and $23-25^{\circ} \mathrm{C}$ for $25-30$ days [5]. The number of adult flies emerged from each group were recorded and analyzed.

Similar to experiments I and II, emerged flies were separated into male and female using a chiller set at $4{ }^{\circ} \mathrm{C}$. The flies were kept in cages (diameter of $20 \mathrm{~cm}$ length and width of $5 \mathrm{~cm}$ ) at a density of 30-40 flies per cage with netting on top and bottom for feeding and collection of the larvae. The emerged males were divided into groups of 20 insects each. The males were irradiated at different ages of emergence using a dose $120 \mathrm{~Gy}$. The 1 st groups of 20 male flies were kept in a cage at the 1 st day of emergence and irradiated with $120 \mathrm{~Gy}$ while the $2 \mathrm{nd}$ and 3 rd groups of 20 male flies were irradiated after three and ten days of emergence, respectively. As a control group, 20 non-irradiated (fertile) male flies were used. Feeding was done three times a week using 96\% irradiated bovine blood [5]. Feeding was finally quitted and survival was recorded on days 2,5 and 8 after 10 days of emergence. The experiment was designed in a completely randomized design (CRD) in three replications.

Data entry and analysis were done using Microsoft Excel and SPSS Version 15.0 respectively. Data were transformed using Arcsine transformation when necessary. one way ANOVA was used to observe the effects of treatment (irradiation) on number of pupae, number of $\mathrm{F} 1$ progeny, number of abortion of egg/larvae and the effect of treatment (irradiation) on survival of male fly. Significant difference between the means was separated using Tukey's honestly significant difference (HSD) test [7].

\section{Results}

\subsection{Effect of Irradiation Versus Abortion of Egg/Larvae}

Results on the rate of aborted egg/larvae on females mated with males irradiated with different doses over a period of 20- 30 days are presented in Table 1 . The number of aborted egg/larvae in females mated with males irradiated at dose of $80 \mathrm{~Gy}$ was not significantly different from those treated with 100Gy, 60Gy and the controls over 20 days of observation after treatment $(\mathrm{P}>0.05)$ whereas, Males irradiated with 100Gy and mated with females however caused significantly higher abortion than those treated with 60Gy and the controls $(\mathrm{P}<0.05)$ (Table 1).

The number of aborted egg/larvae in cages following irradiation using doses of $80 \mathrm{~Gy}, 100 \mathrm{~Gy}$, and 120Gy for 30 days of observation after inseminating /mating females with sterile male in the female cages caused significantly higher than those irradiated with 60Gy dose and the controls $(\mathrm{P}<0.05)$ (Appendix 5). However, the numbers of aborted egg/larvae were not significantly different in males treated with doses of $80 \mathrm{~Gy}, 100 \mathrm{~Gy}$ and $120 \mathrm{~Gy}$ mated to females over 30 days of observation after treatment $(\mathrm{P}>0.05)$ (Table 1$)$.

As presented in Table 2, abortion of egg/larvae in females mated with males treated with doses, 100Gy and 120Gy was not significantly different over 20, 25 and 30 days of observation after treatments $(\mathrm{P}>0.05)$. Similarly, females mated with males irradiated at a dose of $60 \mathrm{~Gy}$ did not show significant different in abortion of egg/larvae over 20, 25 and 30 days of observation after treatment $(\mathrm{P}>0.05)$. Flies irradiated with doses including 80Gy, 100Gy and 120Gy caused abortion of egg/larvae significantly higher than those treated with 60Gy and the controls for 30 day of observation after treatment. In the present study, the highest rate of aborted egg/larvae was observed at highest dose (120Gy) (Table 1).

Table 1. The magnitude of egg/larvae abortion in female flies mated with sterile male at different dose of irradiation over days of observation after treatment.

\begin{tabular}{llll}
\hline \multirow{2}{*}{ Treatments } & \multicolumn{3}{l}{$\begin{array}{l}\text { Abortion of egg/larvae over days after treatment } \\
\text { (mean } \pm \text { se) }\end{array}$} \\
\cline { 2 - 4 } & $\mathbf{2 0}$ & $\mathbf{2 5}$ & $\mathbf{3 0}$ \\
\hline 60Gy & $0.33 \pm 0.33 \mathrm{c}$ & $1 \pm 0.58 \mathrm{~cd}$ & $0.33 \pm 0.33 \mathrm{~b}$ \\
80Gy & $1.33 \pm 0.33 \mathrm{bc}$ & $2.33 \pm 0.33 \mathrm{bc}$ & $2.67 \pm 0.67 \mathrm{a}$ \\
100Gy & $2.33 \pm 0.33 \mathrm{ab}$ & $3.67 \pm 0.33 \mathrm{~b}$ & $3.67 \pm 0.33 \mathrm{a}$ \\
120Gy & $3.00 \pm 0.58 \mathrm{a}$ & $5.33 \pm 0.33 \mathrm{a}$ & $4.33 \pm 0.33 \mathrm{a}$ \\
Control & $0.00 \pm 0.00 \mathrm{c}$ & $0.33 \pm 0.33 \mathrm{~d}$ & $0.00 \pm 0.00 \mathrm{~b}$ \\
\hline
\end{tabular}

Mean within the column followed by the same letters are not significantly different at $\alpha=0.05$, Tukey Student Test (HSD).

\subsection{Effects of Irradiation on Pupae Production over Observation Periods}

The number of pupae produced by females mated with males irradiated with different doses over a period of 18- 30 
days and the blocked pupae found during dissecting females at 30 days after treatment are presented in Table 2. Results showed that for 18 day of observation after treatment, insects (males) treated with irradiations doses of 60Gy, 80Gy, 100Gy, 120Gy mated with females resulted in significantly lower number of pupae than the controls $(\mathrm{P}<0.05)$. However, there was no significant between insects (males) treated with different doses mated to females in terms of pupae production over a period of 18 days observation after treatment $(\mathrm{P}>0.05)$.

The number of pupae produced in female mated with males treated by $80 \mathrm{~Gy}, 100 \mathrm{~Gy}$ and $120 \mathrm{~Gy}$ doses were significantly lower than the controls over 18, 22, 26 and 30 days of observation after treatments $(\mathrm{P}<0.05)$. However, the number of pupae produced by females mated with males treated with doses of $80 \mathrm{~Gy}, 100 \mathrm{~Gy}$ and $120 \mathrm{~Gy}$ were not significantly different on the same days of observation after treatment $(\mathrm{P}>0.05)$ (Table 2$)$.

The results showed that there was no significant difference in pupae production in flies treated with doses $60 \mathrm{~Gy}, 80 \mathrm{~Gy}$, 100Gy, and 120Gy over 26 days of observation after treatment. But the highest pupae reduction was observed in females mated with males treated with dose of 120Gy (Table 2) as expected.
As presented in Table 5, the number of pupae produced by females mated with males irradiated at dose of 60Gy was not significantly different from $80 \mathrm{~Gy}, 100 \mathrm{~Gy}$ and the controls over 22 days of observation after treatment $(\mathrm{P}>0.05)$ whereas, in males treated with $80 \mathrm{~Gy}$ and $100 \mathrm{~Gy}$ mated with females, the number of pupae produced were significantly lower than the control over 22 day of observation after treatment $(\mathrm{P}<0.05)$ (Table 2).

Moreover, numbers of blocked pupae during dissecting was recorded in females mated with males irradiated at a dose of $80 \mathrm{~Gy}$ was not significantly different from those males treated with $120 \mathrm{~Gy}, 100 \mathrm{~Gy}$ and $60 \mathrm{~Gy}(\mathrm{P}>0.05)$. On the other hand, the number of blocked pupae in insects treated with 60Gy mated with females was significantly higher than 120 Gy and 100Gy irradiated males $(\mathrm{P}<0.05)$.

Results also showed that, the number of blocked pupae found in females during dissecting recorded in males treated with 80Gy, 100Gy and 120Gy mated with females were significant lower than the controls $(\mathrm{P}<0.05)$. However, the number of blocked pupae found in females mated with males treated with 80Gy, 100Gy and 120Gy were not significantly different $(\mathrm{P}>0.05)$. In general, results of these experiments showed that production of pupae was inversely proportional to doses.

Table 2. Mean number of pupae produced by females after mating with treated males against doses of irradiation.

\begin{tabular}{|c|c|c|c|c|c|}
\hline \multirow{2}{*}{ Treatments } & \multicolumn{5}{|c|}{ Pupae produced over days after treatment (mean \pm se) } \\
\hline & 18 & 22 & 26 & 30 & Blockage of pupae \\
\hline 60Gy & $0.67 \pm 0.33 \mathrm{~b}$ & $3.33 \pm 0.33 \mathrm{ab}$ & $3.33 \pm 0.88 \mathrm{~b}$ & $4.33 \pm 0.33 \mathrm{a}$ & $2.67 \pm 0.33 \mathrm{ab}$ \\
\hline 80Gy & $0.33 \pm 0.33 \mathrm{~b}$ & $2 \pm 0.58 \mathrm{bc}$ & $1.67 \pm 0.33 \mathrm{~b}$ & $2 \pm 0.58 \mathrm{~b}$ & $1 \pm 0.58 \mathrm{bc}$ \\
\hline 100Gy & $0.00 \pm 0.00 \mathrm{~b}$ & $0.33 \pm 0.33 \mathrm{bc}$ & $1.33 \pm 0.33 b$ & $0.67 \pm 0.33 b$ & $0.67 \pm 0.33 c$ \\
\hline 120Gy & $0.00 \pm 0.00 \mathrm{~b}$ & $0.00 \pm 0.00 \mathrm{c}$ & $0.67 \pm 0.33 \mathrm{~b}$ & $0.33 \pm 0.33 b$ & $0.33 \pm 0.33 \mathrm{c}$ \\
\hline control & $3 \pm 0.58 \mathrm{a}$ & $5.33 \pm 1.45 \mathrm{a}$ & $6.33 \pm 0.88 \mathrm{a}$ & $6 \pm 1 \mathrm{a}$ & $4 \pm 0.58 \mathrm{a}$ \\
\hline
\end{tabular}

Mean within the same column followed by the same letters are not significantly different at $\alpha=0.05$, Tukey Student Test (HSD).

\subsection{Effects of Irradiation on Adults Fly Emergence}

Results on number of emerged adults from pupae collected after treated males with different doses mated with females from 25-30 days of observation are presented in Table 3. The number of emerged adults from all treated males with doses, 60Gy, 80Gy, 100Gy, 120Gymated with females and the number of collected pupae were significantly lower than the control over 25 days of observation after treatment $(\mathrm{P}<0.05)$. But the comparison on the number of emerged adults emerged from pupae produced by females mated with males treated by different doses were not significantly different over 25 days of observation after treatment $(\mathrm{P}>0.05)$. Similarly, for all days of observation after treatment the number of emerged adults from collected pupae, produced by females mated with males treated by $80 \mathrm{~Gy}, 100 \mathrm{~Gy}$ and 120Gy were not significantly different $(\mathrm{P}>0.05)$ (Table 3$)$.

Emergence of adults from collected pupae produced by females mated with males treated with dose of 80 Gy over 30 day of observation after treatment were not significantly different than males treated with doses of 60Gy, 100Gy and 120Gy $(\mathrm{P}>0.05)$. However, males treated with 60Gy mated with female, adult emerged from pupae were significantly higher than from those treated with $100 \mathrm{~Gy}$ and $120 \mathrm{~Gy}$ over 30 days of observation after treatment $(\mathrm{P}<0.05)$. Results showed that emergence of adults from pupae produced by treated males were inversely proportional to doses.

Table 3. Mean number of adults flies emergence from pupae produced by female mated with males subjected to different irradiations doses.

\begin{tabular}{llll}
\hline \multirow{2}{*}{ Treatments } & \multicolumn{4}{l}{ Adult emergence versus days after treatment (mean \pm se) } \\
\cline { 2 - 4 } & $\mathbf{2 5}$ & $\mathbf{2 7}$ & $\mathbf{3 0}$ \\
\hline 60Gy & $1.33 \pm 0.33 \mathrm{~b}$ & $4.33 \pm 0.33 \mathrm{~b}$ & $2.33 \pm 0.33 \mathrm{~b}$ \\
80Gy & $0.00 \pm 0.00 \mathrm{~b}$ & $1.67 \pm 0.33 \mathrm{c}$ & $1.67 \pm 0.33 \mathrm{bc}$ \\
100Gy & $0.00 \pm 0.00 \mathrm{~b}$ & $0.33 \pm 0.33 \mathrm{c}$ & $0.33 \pm 0.33 \mathrm{c}$ \\
120Gy & $0.00 \pm 0.00 \mathrm{~b}$ & $0.33 \pm 0.33 \mathrm{c}$ & $0.00 \pm 0.00 \mathrm{c}$ \\
control & $5 \pm 0.57 \mathrm{a}$ & $8.33 \pm 0.33 \mathrm{a}$ & $3.67 \pm 0.33 \mathrm{a}$ \\
\hline
\end{tabular}

Means within the same column followed by the same letters are not significantly different at $\alpha=0.05$, Tukey Student Test (HSD).

\subsection{Effects of Sterility (Irradiation) on Abortion of Egg/Larvae}

The number of aborted egg/larvae at different ratios of sterile to fertile males mated with females at different days of observations is presented in Table 4. Results showed that number of aborted egg/larvae in females mated with groups 
contains 9 sterile to 1 fertile male, 7 sterile to 3 fertile males and 5 sterile to 5 fertile males for 25 and 30 days of observation after treatment were significantly higher than the batch consisting 3 sterile to 7 fertile males and all fertile positive control males $(\mathrm{P}<0.05)$.

Comparison of two groups, ( 3 sterile to 7 fertile males and all fertile positive control) for all days of observations after treatment in terms of number of aborted eggs/larvae were not significantly difference $(\mathrm{P}>0.05)$. Similarly, for all days of observation after treatment, groups containing 7 sterile to 3 fertile males and 5 sterile to 5 fertile males were not significantly difference $(\mathrm{P}>0.05)$ in number of aborted egg/larvae (Table 4).

The number of aborted egg/larvae in females mated with groups contains 9 sterile to 1 fertile male were not significantly different from those with 7 sterile to 3 fertile males, 5 sterile to 5 fertile males and all sterile negative control over 20 day of observation after treatment $(\mathrm{P}>0.05)$ whereas, 7 sterile to 3 fertile males and 5 sterile to 5 fertile males were significantly lower than all sterile negative control (10 sterile males with 30 females) over 20 day of observation after treatment $(\mathrm{P}<0.05)$. This experiment showed that the number of aborted egg/larvae was observed to be higher in groups containing greater numbers of sterile males than fertile males.

Table 4. Abortion of egg/larvae at different ratio of sterile to fertile males mated with females against days of observation post treatment.

\begin{tabular}{llll}
\hline \multirow{2}{*}{$\begin{array}{l}\text { Treatments(Sterile: } \\
\text { fertile males ratio) }\end{array}$} & \multicolumn{4}{l}{$\begin{array}{l}\text { Abortion of egg/larvae by day after } \\
\text { treatment (mean } \pm \text { se) }\end{array}$} \\
\cline { 2 - 4 } & $\mathbf{2 0}$ & $\mathbf{2 5}$ & $\mathbf{3 0}$ \\
\hline $9: 1$ & $3.33 \pm 0.33 \mathrm{ab}$ & $4 \pm 0.58 \mathrm{a}$ & $4.33 \pm 0.33 \mathrm{~b}$ \\
$7: 3$ & $1.67 \pm 0.33 \mathrm{bc}$ & $4 \pm 0.58 \mathrm{a}$ & $3.67 \pm 0.33 \mathrm{~b}$ \\
$5: 5$ & $1.67 \pm 0.33 \mathrm{bc}$ & $3.67 \pm 0.33 \mathrm{a}$ & $3.33 \pm 0.33 \mathrm{~b}$ \\
$3: 7$ & $0.00 \pm 0.00 \mathrm{c}$ & $1 \pm 0.00 \mathrm{~b}$ & $0.67 \pm 0.33 \mathrm{c}$ \\
$0: 10$ & $0.00 \pm 0.00 \mathrm{c}$ & $0.33 \pm 0.33 \mathrm{~b}$ & $0.00 \pm 0.00 \mathrm{c}$ \\
$10: 0$ & $3.67 \pm 0.67 \mathrm{a}$ & $5 \pm 0.58 \mathrm{a}$ & $6 \pm 0.58 \mathrm{a}$ \\
\hline
\end{tabular}

Mean within the same column followed by the same letters are not significantly different at $\alpha=0.05$, Tukey Student Test (HSD).

\subsection{Effects of Sterile to Fertile Males Mated with Females on Pupae Production}

Results on the number of pupae produced by females mated with sterile to fertile males at different ratios over a period of
18- 30 days and the numbers of blocked pupae from dissected females after 30 days are presented in Table 5. The number of pupae produced by females mated with sterile to fertile males at a ratio of 7 sterile to 3 fertile males was not significantly different from a ratios of 9 sterile to 1 fertile male, 5 sterile to 5 fertile males, 3 sterile to 7 fertile males and all sterile negative control over 26 and 30 days of observation after treatment $(\mathrm{P}>0.05)$. On the other hand, 5 sterile to 5 fertile males and 3 sterile to 7 fertile males mated with females produced pupae significantly higher than group contain 9 sterile to 1 fertile male and all sterile negative control over 26 and 30 days of observation after treatment $(\mathrm{P}<0.05)$ (Table 5).

The number of pupae produced by females mated with males in the ratio of 9 sterile to 1 fertile male and all sterile negative control for all days of observation after treatment were not significantly different $(\mathrm{P}>0.05)$. Similarly, the number of pupae produced by females mated with males for groups containing 3 sterile to 7 fertile males and the fertile positive control were not significantly different over 18 and 30 days of observation after treatment $(\mathrm{P}>0.05)$ (Table 5). Even though, groups containing 9 sterile to 1 fertile male mated with females caused reduction of pupae, the difference was not statistically different from those groups containing 7 sterile to 3 fertile males and 5 sterile to 5 fertile males over 18 day of observation after treatment.

Moreover, the number of blocked pupae found in females groups contain 9 sterile to 1 fertile male, 7 sterile to 3 fertile males and 5 sterile to 5 fertile males groups had no significant difference as compared with all sterile negative controls $(\mathrm{P}>0.05)$. Results showed that the number of blocked pupae observed by dissecting females mated with males at a ratio of 5 sterile to 5 fertile males was not significantly different from the other groups including, 9 sterile to 1 fertile males, 7 sterile to 3 fertile males, 3 sterile and 7 fertile males and all sterile negative control $(\mathrm{P}>0.05)$. However, similar to the batch containing 3 sterile to 7 fertile males mated to females, the number of blocked pupae during dissecting was significantly higher than the batches consisting 9 sterile to 1 fertile male, 7 sterile to 3 fertile males and all sterile negative control $(\mathrm{P}<0.05)$. In sum, the results in this experiment showed that the increased number of pupae produced by females was directly related with groups containing greater number of fertile males mated with females.

Table 5. Mean number of pupae produced by females mated with fertile and sterilemales at different ratios against days of observation after treatment.

\begin{tabular}{llllll}
\hline \multirow{2}{*}{ Treatments (Sterile: fertile males ratio) } & \multicolumn{2}{l}{ Pupae produced over days after treatment (mean \pm se) } \\
\cline { 2 - 6 } & $\mathbf{1 8}$ & $\mathbf{2 2}$ & $\mathbf{2 6}$ & $\mathbf{3 0}$ & Blockage of pupae \\
\hline $9: 1$ & $0.00 \pm 0.00 \mathrm{~b}$ & $0.67 \pm 0.33 \mathrm{de}$ & $0.67 \pm 0.33 \mathrm{c}$ & $0.33 \pm 0.33 \mathrm{c}$ & $0.33 \pm 0.33 \mathrm{c}$ \\
$7: 3$ & $0.33 \pm 0.33 \mathrm{ab}$ & $2 \pm 0.00 \mathrm{~d}$ & $2 \pm 0.58 \mathrm{bc}$ & $1.33 \pm 0.33 \mathrm{bc}$ & $0.67 \pm 0.33 \mathrm{c}$ \\
$5: 5$ & $0.67 \pm 0.33 \mathrm{ab}$ & $4.33 \pm 0.33 \mathrm{c}$ & $3.67 \pm 0.33 \mathrm{~b}$ & $2.33 \pm 0.33 \mathrm{ab}$ & $1.33 \pm 0.33 \mathrm{bc}$ \\
$3: 7$ & $2 \pm 0.58 \mathrm{a}$ & $6.33 \pm 0.33 \mathrm{~b}$ & $3.67 \pm 0.88 \mathrm{~b}$ & $2.67 \pm 0.33 \mathrm{ab}$ & $3 \pm 0.58 \mathrm{ab}$ \\
$0: 10$ & $2 \pm 0.58 \mathrm{a}$ & $9.00 \pm 58 \mathrm{a}$ & $7 \pm 1 \mathrm{a}$ & $3.33 \pm 0.33 \mathrm{ab}$ & $4 \pm 0.58 \mathrm{a}$ \\
$10: 0$ & $0.00 \pm 0.00 \mathrm{~b}$ & $0.33 \pm 0.33 \mathrm{e}$ & $0.67 \pm 0.33 \mathrm{c}$ & $0.00 \pm 0.00 \mathrm{c}$ & $0.33 \pm 0.33 \mathrm{c}$ \\
\hline
\end{tabular}

Mean within the same column followed by the same letters are not significantly different at $\alpha=0.05$, Tukey Student Test (HSD). 


\subsection{Effects of Sterile to Fertile Males Mated with Females on Emergence of Adults from Pupae}

The emergence of adults from pupae produced by females after mating with different ratio of sterile to fertile males from day 25-30 is presented in Table 6. Results showed that the number of adults emerged from pupae produced by females mated with all groups of sterile to fertile males ratio and all sterile negative control were significantly lower than all fertile positive control (10 fertile males allowed to mate 30 females) over 30 and 27 days of observation after treatment $(\mathrm{P}<0.05)$.

Over 27 and 30 days of observations after treatment, the emergence of adults from pupae produced by groups containing lower number of fertile males ( 9 sterile to 1 fertile male and 7 sterile to 3 fertile males) were significantly lower than groups containing greater number of fertile males ( 5 sterile to 5 fertile males and 3 sterile to 7 fertile males) $(\mathrm{P}<0.05)$. But, comparing each ratio within the groups (in lower number of fertile male ratios and higher number of fertile males ratios), showed not significant difference in number of emerged adults $(\mathrm{P}>0.05)$ (Table 6).

Results in this part of the experiments showed that number of emerged adults from pupae produced by females mated with males at the ratio of 5 sterile to 5 fertile males and 3 sterile to 7 fertile males were not significantly different from those with 9 sterile to 1 fertile male, 7 sterile to 3 fertile males, all sterile negative control and all positive fertile control over 25 days of observation after treatment $(\mathrm{P}>0.05)$ (Table 6). In the contrary, batches consisting of 9 sterile to 1 fertile male, 7 sterile to 3 fertile males and all sterile negative control were significantly lower than all fertile positive control over the same days of observation after treatment $(\mathrm{P}<0.05)$. This experiment showed that emergence of adults from pupae produced by large number of sterile males ratio mated with females was inversely proportional.
Table 6. Adult flies emergence from pupae produced by sterile to fertile males mated to females versus day of observation.

\begin{tabular}{llll}
\hline \multirow{2}{*}{$\begin{array}{l}\text { Treatments (Sterile: } \\
\text { fertile males ratio) }\end{array}$} & \multicolumn{3}{l}{$\begin{array}{l}\text { Adult emergence day after treatment } \\
(\mathbf{m e a n} \pm \mathbf{s e})\end{array}$} \\
\cline { 2 - 4 } & $\mathbf{2 5}$ & $\mathbf{2 7}$ & $\mathbf{3 0}$ \\
\hline $9: 1$ & $0.00 \pm 0.00 \mathrm{~b}$ & $0.33 \pm 0.33 \mathrm{c}$ & $0.00 \pm 0.00 \mathrm{c}$ \\
$7: 3$ & $0.33 \pm 0.33 \mathrm{~b}$ & $1.33 \pm 0.33 \mathrm{c}$ & $1.33 \pm 0.33 \mathrm{c}$ \\
$5: 5$ & $0.67 \pm 0.33 \mathrm{ab}$ & $4.67 \pm 0.33 \mathrm{~b}$ & $4 \pm 0.58 \mathrm{~b}$ \\
$3: 7$ & $1.33 \pm 0.33 \mathrm{ab}$ & $5.33 \pm 0.67 \mathrm{~b}$ & $5.33 \pm 0.33 \mathrm{~b}$ \\
$0: 10$ & $2 \pm 0.58 \mathrm{a}$ & $8.33 \pm 0.33 \mathrm{a}$ & $9 \pm 1.16 \mathrm{a}$ \\
$10: 0$ & $0.00 \pm 0.00 \mathrm{~b}$ & $0.33 \pm 0.33 \mathrm{c}$ & $0.00 \pm 0.00 \mathrm{c}$ \\
\hline
\end{tabular}

Mean within the same column followed by the same letters are not significantly different at $\alpha=0.05$, Tukey Student Test (HSD).

\subsection{Effects of Gamma Irradiation on Survivals of Male G. Pallidipes over Days of Emergence Following Treatment}

Results on survivals of adult male G. pallidipes irradiated with the dose of 120Gy at different ages of emergence over a period of 2-8 days are presented in Table 7. The number of survived sterile males following irradiation at the dose of 120 Gy males irradiated one day after emergence and males irradiated ten days after emergence were significantly lower than males irradiated three days emergence after emergence and the control over 2 and 8 days of observation after treatment $(\mathrm{P}<0.05)$. However, the number of survived sterile males after irradiation at $120 \mathrm{~Gy}$ males irradiated one day after emergence was not significantly different from males irradiated ten days after emergence. Similarly, the number of those emerged on day three sterile males were not significantly different from the control for 2 and 8 days of observation after treatment $(\mathrm{P}>0.05)$ (Table 7).

The number of survived sterile males in all treatments (males irradiated one days after emergence, males irradiated three days after emergence and males irradiated ten days after emergence) were not significantly different from the control over 5 days of observations after treatment $(\mathrm{P}>0.05)$. In general, this experiment showed that adult males irradiated three days post emergence survived more than males irradiated one aged and ten aged after emergence.

Table 7. Mean number of survival males after ten day of feeding by irradiation at different age of emergence.

\begin{tabular}{|c|c|c|c|}
\hline \multirow{2}{*}{ Treatments } & \multicolumn{3}{|c|}{ mean \pm se Survival by days after treatment } \\
\hline & 2 & 5 & 8 \\
\hline Males irradiated one days after emergence & $17 \pm 0.58 \mathrm{a}$ & $9.67 \pm 0.33 \mathrm{a}$ & $2.33 \pm 0.33 \mathrm{a}$ \\
\hline Males irradiated three days after emergence & $19.33 \pm 0.33 b$ & $9.33 \pm 0.33 \mathrm{a}$ & $4.67 \pm 0.67 b$ \\
\hline Males irradiated ten days after emergence & $17 \pm 0.58 \mathrm{a}$ & $9.00 \pm .58 \mathrm{a}$ & $1 \pm 0.56 \mathrm{a}$ \\
\hline control & $19.67 \pm 0.33 b$ & $9.67 \pm 1.20 \mathrm{a}$ & $5.33 \pm 0.33 b$ \\
\hline
\end{tabular}

Mean within the same column followed by the same letters are not significantly different at $\alpha=0.05$, Tukey Student Test (HSD).

\section{Discussion}

Tsetse flies (Glossinidae) are vector for transmission of the parasites trypanosome causing Nagana among domestic animals and sleeping sickness among human has made them one of the most devastating insect in Africa and Ethiopia in particular.

The results in the present work revealed that the highest dose (120Gy) treated males mated with females showed significantly higher abortion of egg/larvae compared to the lowest dose (60Gy) and untreated control. However, the general trend of the results showed a general increase on aborted egg/larvae in females mated with treated males as 
dose increased. Previous studies indicate that, radiation may be used as genetic control involving the release of irradiated sterile males so that most of the females will lay sterile eggs [8]. The present laboratory based results show that the irradiation effects on male G. pallidipes at different doses (60Gy, 80Gy, 100Gy and 120Gy) mated with females in that the proportion of aborted egg/larvae was dose dependent. These relations showed that sterility with a highest dose (120Gy) may have more effects on the normal reproduction performance of females leading to decreased number of flies over time.

The present investigation indicated that irradiation had effects on male G. pallidipes subjected to different doses (60Gy, 80Gy, 100Gy and 120Gy). The results showed that both the number of pupae produced and the number of adults emerged from pupae produced by females mated with sterile males were inversely proportional to dose. This is in agreement with that by Parker and Mehta [14] in which they indicated that radiation dose absorbed by an insect to induce sterility is the main advantage in sterile insect release program. They further examined that insects those receive too low dose may not be sterile effectively. Other studies also indicate that Irradiation of male insects may result in dominant lethal mutations in the sperm, killing spermatogonial cells, inactivation of sperm and weakening of males [3]. The current results show that at low dose (60Gy) irradiated males mated with females have produced pupae and emerged to adult more or less similar to the controls. However, in the highest dose (120Gy), there was a significant reduction in the number of pupae produced by females mated with sterile males and in the number of emerged adults when compared with those subjected to the lowest dose (60Gy) and the untreated controls.

These results may indicate that in order to fully eradicate tsetse fly using SIT, males need to be treated with highest doses to cause significant reduction of the next generation of the target population. The results of the current experiments showed that production of pupae and emergence of adults from pupae produced by females mated with treated males were inversely proportional to doses, whereas the numbers of aborted egg/larvae were positively correlated to dose.

In addition, observation on the reproductive competitiveness of male G. pallidipes at different ratio of sterile males and fertile males mated with female with the higher number of sterile male than fertile male ( 9 sterile to 1 fertile male) per cage showed significant effects on egg/larvae abortion compared to the lowest number of sterile and fertile males ( 3 sterile to 7 fertile males) and to positive control. The general trend of the result showed that increase sterile males per cage than fertile males led to increased abortion of egg/larvae. Among the different ratios of sterile males and fertile males used, the highest number of sterile to fertile ( 9 sterile to 1 fertile male) was found to have higher effect over the post treatment observation days. A similar previous study indicated that parous female flies when mated with sterile males show imbalance between their uterus content and development of the follicle next in the normal ovulation sequence (A, B, C, D) i.e. uterus becomes empty due to expulsion of a dead embryo or with a degenerating egg in uterus classified as having mated with a sterile males (Van den Bossche et al., 2000). The present results also showed that females mated with sterile males had more abortion of egg/larvae at higher number of sterile males in the cage than fertile males.

The research also shows that in sterile: fertile ratio $(9: 1)$ has resulted in $90 \%$ reduction in pupae production and $95 \%$ reduction in emergence to adult. On the other hand, 7 sterile to 3 fertile male's ratio lead to $75 \%$ reduction in pupae production when compared with that in which the normal males mated with females. These indicate that increasing sterile males in the female cages increases the competitive of sterile males to mate to females than fertile male under the current lab condition. Previous recommendations on sterile males to fertile males ratio in SIT for tsetse fly eradication requires a ratio of 10 sterile to 1 wild male whereas a ratio of 3 sterile to 1 fertile male is recommended for control programs (not for eradication) [15]. Curtis [4], stated that in the 10:1 ratio on strategy, the overwhelming number of sterile males would limit the reproduction of the natural population in proportion to the ratio of sterile to fertile insect (with a 1:1 ratio and a 9:1 ratios, the reproductive capacity of the natural population is reduced by $50 \%$ and $90 \%$ respectively).

The current laboratory experiments also indicated that groups containing 9 sterile to 1 fertile males and 7 sterile and 3 fertile males ratio caused reduction on the number of flies by affecting the normal reproductive activity of female leading to the reduction of pupae and that emerged to adults. On the other hand, groups containing greater number of fertile male ratios had greater number of blocked pupae. Previous workers advise that in order to achieve population eradication using SIT technology in each generation, the ratio of sterile to wild insects should increase and the technique becomes more efficient with lower population densities (inversely-density dependent) [12].

The present study showed that sterile males following 1, 3, and 10 days of emergence survived up to 8 days without food under lab condition indicated that males irradiated three days after emergence from pupae showed more survived from those males irradiated at one and ten days of emergence from pupae. Previous studies show that flies are capable of surviving for more than seven weeks and indicated a population half-life of 7 days for the first six weeks. This assures us that released sterile males live long enough to have opportunity to mate with wild females and to locate hosts in the wild [11]. The present experiments also indicated that males irradiated three days after emergence survived similar duration to the control after treatment. This may indicate that irradiated males may need to rest up to 7 or 10 days before released to the field.

In the current study, the importance of sterilization using appropriate dose, the appropriate ratio of sterile to fertile male and the time at which sterility was done efficiently all are relevant this is in agreement to that by [16], who stated 
that SIT relies on the production of large numbers of the target insect in specialized production centers, the sterilization of the males pupae or adult fly (or sometimes both sexes), and the sustained and systematic release of the sterile males over the target area in numbers large enough in relation to the wild male population to out compete them for wild females.

\section{Conclusions and Recommendations}

\subsection{Conclusions}

The present laboratory studies showed that irradiation effects on male G. pallidipes at different doses (60Gy, 80Gy, 100Gy and 120Gy) mated with females showed that the number of aborted egg/larvae was directly proportional with dose. Results indicated that to eradicate tsetse fly using SIT the highest dose (120Gy) irradiated males mated with females made efficient causing abortion of egg/larvae, reduction of pupae and reduced the number of emerged adult from pupae than the lowest doses.

Similarly this study showed that the number of aborted eggs/larvae was higher in groups containing greater numbers of sterile males than fertile males. On the other hand, the number of pupae produced and adults emerged from pupae was lower in groups where sterile males were more than fertile males mated with females. The effect was inversely proportional.

The present laboratory assessments showed that cage with higher sterile males than the fertile males resulted in larger number of egg/larvae abortion and increased reduction on pupae produced and number of pupae emerged to adult.

On the other hand groups containing greater number of fertile male ratios than sterile male had greater number of blocked pupae. Generally, this experiment showed that, the number of pupae produced by females was directly proportional to the number of fertile males mated with female.

The present experiments also indicated that males irradiated three days after emergence was more survived than one day after emergence and ten days after emergence after treatment. This may indicate that irradiated males may need to rest up to 7 or 10 days before released to the field.

\subsection{Recommendations}

In this study male G. pallidipes was irradiated with a dose of $120 \mathrm{~Gy}$ mated with female caused reduction in number of pupae produced and emerged to adult. Further studies with extended period would help verify these results.

The lowest dose of irradiation with 60Gy males mated with females lead to the production of higher number of pupae and higher number of pupae that emerged to adult. This dose however needs to be verified under field condition at small scale before a final conclusion is made.

In this investigation groups containing 9 sterile to 1 fertile male and 7 sterile to 3 fertile males mated to females were able to eradicate and control of tsetse flies respectively. This again needs further investigation in the field.

However, further research is needed that combines sterile to fertile males ratio with other factors such as feeding, temperature and humidity that determines the releasing of sterile male flies. To ensure the sterility of G. pallidipes in a ${ }^{60} \mathrm{Co}$ Gamma cell 2000 the decay time must be calculated each time of irradiation. Lastly, to know the efficiency of sterility of male to eradicate tsetse fly under field condition further field research is needed before mass field release.

\section{References}

[1] Abebe G. (2005) Current situation of Trypanosomosis. In: review article on: Trypanosomosis in Ethiopia. Ethiop. J Biol Sci 4: 75-121.

[2] Abebe, G., Malone, J. B. and Thompson, A (2004): Geospatial forecast model for tsetse transmitted animal trypanosomosis in Ethiopia. SINET, Ethio. J. Sci.27 (1): 1-8.

[3] Coleman, P. G. and alphey, L. (2004). Editorial: Genetic control of vector populations:and imminent prospect. Tropical medicine and Intrnationl Health, 9:433- 437.

[4] Curtis, C. (1985). Genetic control of insect pests: growth industry or lead balloon? Biological Journal of the Linnean society, 26:359-374.

[5] Feldman, U., Luger, D., Barnot, H., Dengwal, L., Ajagbonna, B., Vreysen, M. J. B., and Van der vloedt, A., (1992). Tsetse fly mass rearing colony management deployment of sterile flies, related research development. In: tsetse control, diagnosis and chemotherapy using nuclear techniques, pp167180 IAEA, Vienna.

[6] Feldman, U. (1994). Guidelines for the Rearing of tsetse Flies Using the Membrane Feeding Technique. In: Techniques of insect rearing for the development of integrated pest and vector; management strategy pp 449-471. J. ochieng- odero, ICIPE Science Press, Nairobi.

[7] Gomez, K. A. and Gomez, A. A. (1984). Statistical Procedures for Agricultural Research. $2^{\text {nd }}$ edn, Chichester, UK, Wiley.

[8] Hasan, M. and Khan, A. R. (1998). Control of stored-product pests by irradiation. Integrated pest Management Reviews, 3: 15-29.

[9] Kumela Lelisa, Delesa Damena, Mohamed Kedir and Teka Feyera (2015). Prevalence of Bovine Trypanosomosis and Apparent Density of Tsetse and Other Biting Flies in Mandura District, Northwest Ethiopia. J Veterinar Sci Technol. 6 (3):1-4

[10] Leak, S. (1998). Tsetse biology and ecology: their role in the epidemiology and control of trypanosomosis. CABI Publishing. Oxford and New York. PP. 568.

[11] Masangi A. and Lehane, M. (1999). A method for method for determining the age of very young tsetse flies (Diptera: Glossinidae) and an investigation of the factors determining head fluorescent levels in newly emerged adults. Bull. Entomol. res. 81, 185-188.

[12] Nagel, P. (1995). Environmental monitoring handbook for tsetse control operations. The scientific Environmental monitoring group (SEMG), MargrafVerlarge. 
[13] Oluwafemi (2014). Tsetse/trypanosomosis challenges and rural poverty in Africa: Implications for food security and MDG. Res. J. Agr. Environ. Manag. 3(3): 158-161.

[14] Parker, A and Mehta, K (2007). Sterile insect technique: a model for doseoptimization for improved sterile insect quality. Florida Entomologist, 90: 88-95.

[15] Takken, W., Oladumade, M., Dengwat, L., Feldman, H., Onah, J., Tenade, S. and Hammann, H. (1986) the eradication of Glossina palpalis palpalisusing traps, insecticides-impregnated target and the sterile insect technique in centeral Nigeria. Bull. Entomol Res.76, 275286.
[16] Van den Bossche P, Doran M and Connor R.(2000). An analysis of trypanocidal drug use in the Eastern Province of Zambia. Acta Trop, 75(2):247-58.

[17] Vreysen M., Saleh K., Ali M., Abdulla A., Zhu Z., Juma K. G, Dyck V., Msangi A. R, Mkonyi P., Feldmann H.(2000). Glossina austeni (Diptera: Glossinidae) eradicated on the island of Unguja, Zanzibar, using the sterile insect technique. J. anim. Ecol.93, 123-135. 